\title{
Photovoice: Young children online English language learning, parents' voices and its implication to educational policy and provision
}

\author{
Kurniawan Yudhi Nugroho ${ }^{1}$ and Zulfa Sakhiyya ${ }^{2}$ \\ ${ }^{1}$ Study Program of English Education, Faculty of Language and Communication Science, Universitas Islam \\ Sultan Agung Jl. Raya Kaligawe Km. 4 Semarang, Central Java, Indonesia \\ ${ }^{1,2}$ Doctoral Degree Program of English Language Education, Pascasarjana, Universitas Negeri Semarang \\ Gedung A, Kampus Paska Sarjana, Jl. Kelud Utara III, Semarang, Central Java, Indonesia
}

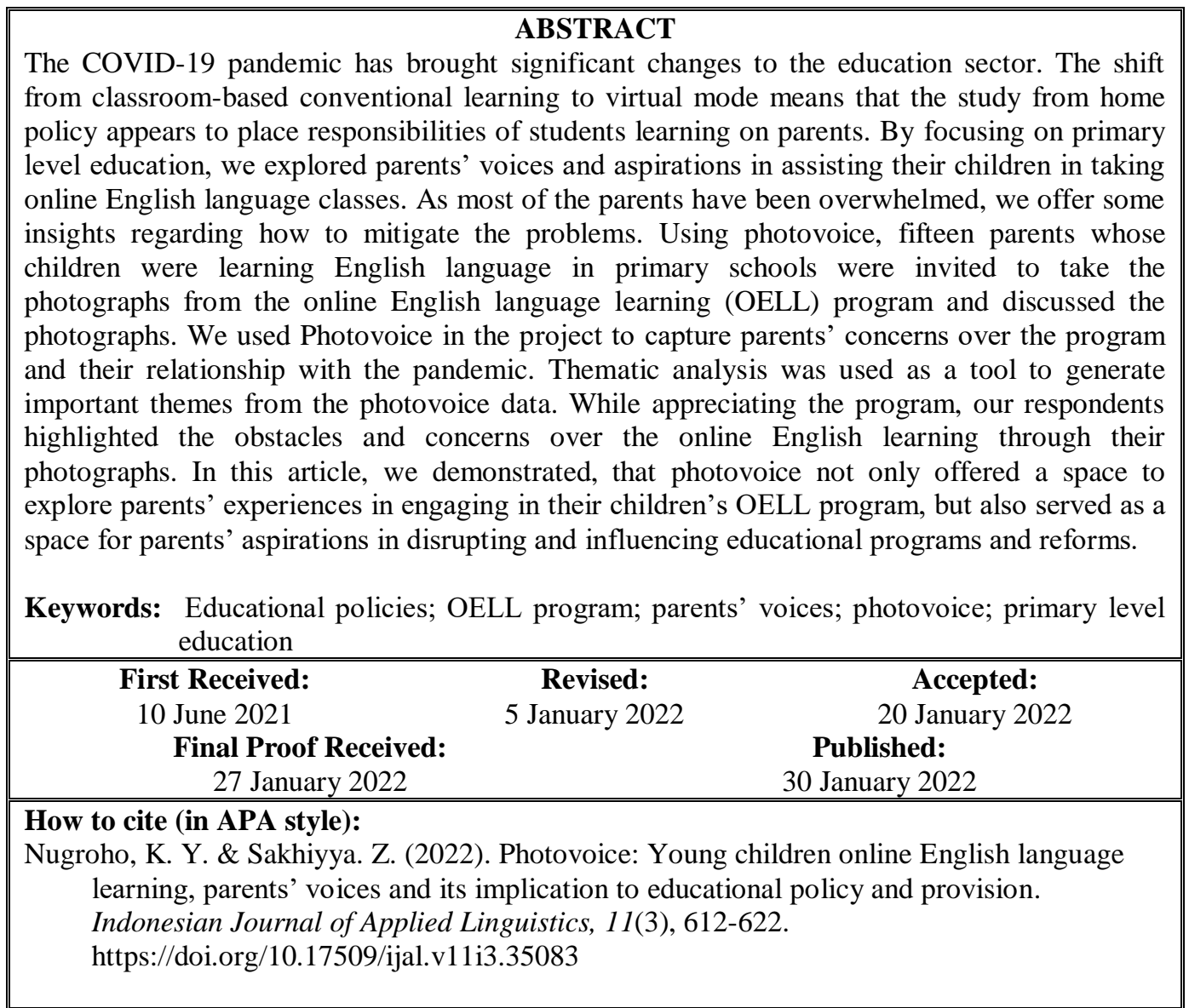

\section{INTRODUCTION}

Not only has the COVID-19 pandemic become a world health problem, but it also has had a major impact on the key sectors, including education. In Indonesia, as of June 6, 2020, there were 646.192 schools, 62.561 .660 students and 3.147.870 teachers directly affected by the crisis (World Bank, 2020). To prevent the transmission of COVID-19, the government issued a policy on compulsory physical distancing intended to control the pandemic (Amir et al., 2020). Consequently, the majority of schools across the archipelago have been temporarily closed. To comply with the policy, educators have been appropriately and timely conforming the curriculum to provide education and sustainably support student academic progresses while staying at home (Lau \& Lee, 2020). Thus, the traditional learning mode was shifted into online.

Despite being useful to support educational activities, especially during the covid-19 pandemic

\footnotetext{
* Corresponding Author

Email: calingasan.kaa@ndu.edu.ph
} 
(Aubrey \& Dahl, 2008; Clements \& Sarama, 2003; Erdogan et al., 2019; Kumi-Yeboah et al., 2020; Plowman et al., 2012), online learning presents a number of issues and challenges (Anitha Kumari et al., 2020; Kim et al., 2005; Mishra et al., 2020; Rasheed et al., 2020). In the case of young children education, online learning has been reported to raise problems generally associated with self-regulation, health, growth, and foreign language development (Bolster et al., 2004; Dong et al., 2020; Lau \& Lee, 2020). Therefore, designs of online learning, particularly foreign language, have to be carefully conceptualized and directed, while counting in the component like social, cultural, and personal artifacts to make this program safe, effective and engaging for children of 21 st century (Arnott \& Yelland, 2020; Clements \& Sarama, 2003; Erdogan et al., 2019).

However, all of these arguments are from the standpoints of scholars and educators; parents' perspective as one of the most important stakeholders of young children education remains largely underexplored (Lan et al., 2020; Okumura, 2020; Tay et al., 2014; Z. Wang et al., 2021). For these reasons, this paper aims to explore the concerns and expectations of parents towards online learning which hereafter focuses on online English language learning (OELL) program for primary school students. To enrich results of qualitative research in TEFL, methods other than group or individual, structured and semi structured or open interviews (Wass et al., 2020) were employed. Through visual methodologies like photovoice, parents were presented with the opportunities to reflectively and actively voice their perspectives, experiences and aspirations to what counts as education during this pandemic.

\section{Photovoice: A Space to Share and Engage}

The use of photovoice in exploring parents' voices falls under a research methodology which promotes participants to take daily photographs of their lived experiences as a way to "document reality, interpret it and participate in negotiating different social interpretation of social phenomena" which lead to social transformation (Malka, 2020, p. 3). In the past, this methodology was employed in healthcare research (Castleden et al., 2008). Recently, their current use has developed into wider contexts of application, for instance, higher education (e.g. Anderson et al., 2019; Ciolan \& Manasia, 2017; Ferdiansyah et al., 2020; Lorusso et al., 2020; Perry, 2006; Stupans et al., 2019; Wass et al., 2020), education policies (Tsang \& Lian, 2020), language and education (Grant, 2019), and social works (Mulder \& Dull, 2014). Despite a number of evidences on the uses of photovoice, research in this methodology barely investigates domain of EFL learning for primary school education.
There are three main purposes identified in photovoice methodologies. Firstly, it aims to provide research participants with venues to document and identify "their emotions, ideas and thoughts about the phenomenon" (Wass et al., 2020, p.2) and it is mainly relevant to concerns and strengths. Secondly, it encourages critical dialogue among individuals and communities about social and political issues affecting their lives through photograph-based group discussion. And thirdly, the voices generated from this might open up possibilities to influence policy makers (Wang \& Burris, 1997). In photovoice research, participants are the ones to take the ownership of designing the research, taking, deciding, and analyzing the photograph, in addition to interpreting and doing continuous reflection on the images in order that they can decide the meaning behind the photograph where process of the investigation is grounded on the cultural background and daily routines of participants (Dodson \& Schmalzbauer, 2005; Green \& Kloos, 2009). This research not only helps participants voice out their lived experience, but also gives researchers access to uncover participants' personal experiences (Ciolan \& Manasia, 2017). It helps open the aspiration of marginalized individuals or communities whose voices is commonly absent from policy discussion (Evans-Agnew \& Rosemberg, 2016). Employing photovoice in a research, design of which and its roles of both participants and researchers should be flexible, while being highly adaptable to the situation as required (Wall \& Higgins, 2006). From the discussion, we learned some reasons why photovoice has often been employed by communities (or researchers) as a strategy to provoke social transformation (Wang \& Burris, 1994).

Although photovoice allows participants to design their own research, decide the photographs, and describe their emotion, ideas and thoughts based on the photographs, and give meanings behind their photographs, they still need to be trained on how to capture the photographs. Therefore, SHOWeD protocol by Wang et al., (2004) becomes an indispensable component in photovoice research. Here are five key questions under this protocol 1) What do you See in the photographs? 2) what is really Happening? 3) How does this relate to Our lives? 4) Why does this problem or strength exist? 5) What can we Do about it? (p. 912). Following the data collection, analyses of the issues are made by presenting not only strengths and concerns of the community, but also checking the existing public resources and assets in order that social issues can be solved (Malka, 2020).

Not only that photovoice is a relevant methodology to investigate social practices (Bennett \& Dearden, 2013; Pierce, 2020; C. C. Wang et al., 2004), but it is also useful in the field of educational 
reforms. Tsang and Lian, (2020) revealed the benefit of photovoice as a way to understand reasons for academic stress in Hongkong and provide students with opportunities to voice their aspiration about current government policies related to education. Seitz et al., (2012) found that photovoice was an effective strategy to provide students with a platform to have their aspiration heard by campus community members and policy makers about a campus smoking policy. Joyce (2018) recognized the advantage of photovoice as a methodology to unravel the elements in the school environment which foster the connection and disconnection to the school. In a higher education setting, photovoice was employed as a research method to investigate students' conception of a good teaching and an effective learning (Wass et al., 2020). Cook et al., (2016) suggested that the use of Photovoice in a research could stimulate an understanding about local sustainability issues and its connection to community and find out which communities are mostly affected by these issues. Photovoice in a research encourages discussion among participants and researchers about critical topics that promote social action to generate solution.

In sum, photovoice provides a space to embrace issues that are lived and experienced, including one in the OELL program as experienced by parents of primary school students. In this paper, we seek to explore the specifics of this prospects, by considering how the OELL program for primary school education can be connected to phenomenological event, characterized by real-life experiences of parents in escorting children, taking the OELL at home. More than that, this photovoice is employed to understand, while deepening our understanding about parents' voices over the program. We also seek to understand how digital records of photographs can serve as productive materials for reflection, introspection, and reinterpretation by considering the confluence between parents' viewpoints of internal and external realities (what happens and what is perceived) and the learning processes of their children. In addition, it considers how the findings can provide contributions to English teachers, EFL curriculum and policy makers at both school and government levels.

\section{METHODS}

Design

This article draws on research data which investigated parents' voices after their series of involvement in assisting their children in the OELL and its contribution to educational policies and changes from the perspective which allowed us to collect data other than words, and numbers, such as photographs. Photographs can be a vehicle to develop critical dialogue, express, share and critically reflect real-life experiences and knowledge about social concerns influencing individuals or communities, at the end it develops social awareness of the communities leading to social changes (Wang $\&$ Burris, 1997). For these reasons, photovoice was selected as methodological basis to conduct the present study. In addition, the selection of photovoice for the study was closely grounded on how this methodology enabled the research participants to have control over the research process: they decided what photographs to capture, the meaning behind the photographs and which photographs were clearly representing their concerns on the social issues affecting their lives.

\section{Participants}

This study was conducted in both public and private primary schools in Central Java, Indonesia. Fifteen parents whose children were taking English class at schools were purposively recruited as participants of the study. They were aged between $30-50$ years old and had diverse educational, and professional backgrounds. Most of whom had two children, some had one or three, but none had more than three children (see Table 1 for detail). This was a case study limited to space and time in the midst of the pandemic. Living in different neighborhoods, and having their children go to different schools, the participants were not connected one another. However, they know directly or indirectly the members of this research, thus, possibility to gain trust and openness from the participants were opened. During the study, the participants were promoted to take photographs of what they perceived to be important during their assisting children taking the OELL. At the end, they had to select five photographs which truly represented recent condition they experienced to influence their lives. All the names of participants enclosed in the study were pseudonyms.

Table 1

Participants' Demographics: Age Range, Educational Background, Job, Number of Children

\begin{tabular}{llc}
\hline Participants & \multicolumn{1}{c}{ Category } & $\mathbf{N}$ \\
\hline Age range & $>30 \quad 0$ \\
& $31-40$ years & 14 \\
& $41-50$ years & 1 \\
Educational & Senior high school degree & 0 \\
qualification & Bachelor degree & 10 \\
& Master degree & 5 \\
& Doctoral degree & 0 \\
Job & Government & 4 \\
& State owned enterprise & 0 \\
& Private enterprise/ organization & 11 \\
& Privately owned business & 0 \\
Number of & Unemployed & 0 \\
children & One child & 4 \\
& Two children & 8 \\
& Three children & 3 \\
& Four children or more & 0 \\
\hline
\end{tabular}




\section{Procedures}

We contacted the potential research candidates by phone. Direct contact was avoided as the study was conducted during the Covid-19 pandemic. In the session, we introduced the participants to the aims of this study to see their acceptance or rejection upon the offer to join the program. From the 20 (twenty) candidates we selected, only 15 (fifteen) confirmed to be available. Following the confirmation, we asked them to willingly sign a consent letter we provided. Before the project began, the participants were instructed on how to use the camera to properly take the photographs, and most importantly to avoid violating the codes of ethics in the society. After the session ended, they began to capture the images by following Wang et al.'s (2004) SHOWeD protocols based on the theme "parents' voices on young children OELL". These protocols suggested five primary questions to ask 1) What do you see in the photo? 2) what is really happening? 3) How does this relate to our lives? 4) Why does this problem or strength exist? And 5) What can we do about it? This project lasted for seventh months. It began in the end of July 2020 and finished in the end of February, 2021. After we received the photographs, we contacted the participants through online meeting platform such as Google meet. This contact aimed at delving information. We asked the participants to select five photographs representing condition they experienced pursuant to the proposed themes. We discussed these photographs intensively based on SHOWeD protocols as earlier instructed. This communication lasted about 15 to 50 minutes. All the conversations were recorded for the benefit of analysis.

\section{Analyses}

The data collected were analyzed by using Braun and Clarke's (2006) thematic analysis technique. After transcribing and immersing ourselves with the data, we coded and then reviewed, and categorized the themes in the data. Guided by our research question, in these analytical processes we focused on underlying sets of interconnected ideas that have been drawn upon and addressed during online learning. Results of the analyses and categorization were then developed into themes along with the photographs to describe the participants' concerns on the condition of OELL during the pandemic of COVID-19 and describe the needs and expectations of the parents towards the application of the program through the use of Photovoice. Completed with the theme development, data were reorganized in a word format and presented back to the participants in order to check, comments and provide suggestion for completeness of data. Based on the follow up, we received some feedbacks on the wordings. Likewise, one of the participants suggested us to add little more factual information about the photographs she took in order to comprehensively represent her concerns.

\section{FINDINGS \\ Parents Concerns on the OELL Program During the Pandemic of COVID-19 \\ Students' Behaviors During OELL Program}

The theme of learning behavior emerged from a number of pictures with similar statements we received from the parents. To find out the true meanings behind the photographs, we invited the parents for discussion via Google meet application. Given that it was not easy for the parents to get together at the proposed schedule. We contacted them separately based on their availability. Our discussions revealed, the application of OELL had imposed their children with numerous challenges and problems during their involvement in the program (see figure 1).

\section{Figure 1}

Feeling Bored of Participating in a Face to Face OELL Class and Finding Other Activities While the Class in Progress
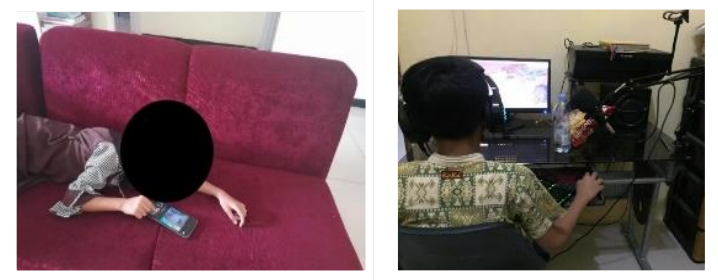

Some parents recognized, their children were not always able to join the class due to limited facilities such as laptop, cellphone and internet. They expressed the children have limited attention span, and found themselves bored as they had to sit and listen to their teacher in a fairly long learning duration; the internet signal was unstable; and the teacher' voices were not clear. Therefore, the children found it difficult to understand their teacher's explanation, especially in English. Many were often quiet and unresponsive, getting less attention from and less interaction with their teacher. Emotional connection among teachers and the children was hardly established and activities exposed the children physically and non-physically to the lessons were rarely made during the OELL class.

Notably, the parents believed employing the concept of this learning in a longer period of time might bring negative effect to children's future cognitive and EFL developments. Furthermore, our data showed that parents started to complain about their children's indiscipline, disobedient, and rebellious behavior, especially while learning about the school subjects at home, including English. A couple of parents experienced rejections from their child to work on both school assignments and final 
school assessments. Despite the challenges and problems of OELL, the parents admitted this program helped their children autodidactically develop skill on IT literacy in which they might not get it from their formal education.

\section{EFL Development During OELL Program}

The way parents deal with their children's online learning is not only psychological, but also involves cognition (Erdogan et al, 2019). Although OELL class is useful to sustain the English language learning during the pandemic, our findings highlighted that the parents still worried about results of the training. Rather than mainly developing students' English language skills and other essential characters such as self-assessment on understanding, sense of responsibility for academic challenges, and self-regulatory aspects as required for development, most parents recognized the OELL class was too much directed to content-oriented task completion such as multiple choices and filling the blank. Consequently, OELL did not appear to be promising in term of helping learners practically develop their English language skills. See Figure 2 for the photographs the parents shared about the program contributions to their children EFL development. These photographs demonstrate the children had a pile of schoolwork and experienced a slow progress of learning. Despite facing the challenges, the children spent a lot of time playing, especially, when their parents were away for office. As a result, the schoolwork would be completed, only if the parents helped them finish the tasks. This study had further seen that activities in the program and the assignments less contributively developed the children's English language skills. Some parents completed their children home-assignments, takehome quizzes and school assessments. Making the children do their school assignments and concentrate on the online learnings were truly a tough job for the parents. While learning at home online, the children were often faced with too many distractions, for example, noises, cell phones, TV, games, toys, brothers and sisters.

\section{Figure 2}

(a) Slow Progress of English Language Development and (b) Overloaded with Schoolwork

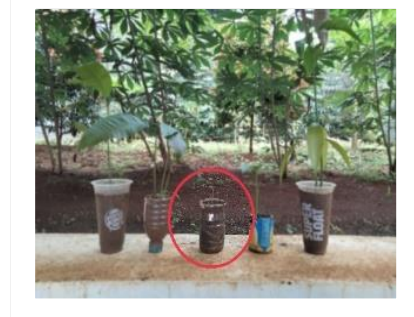

(a)

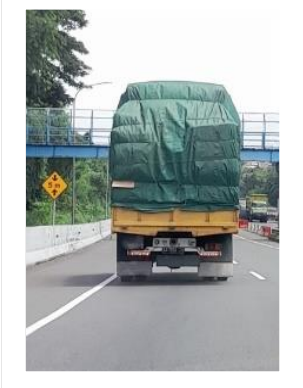

(b)

\section{Sources of Challenges Leading Parents to Stress during OELL Program}

Our findings from collected photographs and discussion with the parents showed their voices about the OELL program. Not only did the findings uncover the parents' voices on their children's progress of English language learning and behaviors, but also explained about issues related to the sources of challenges leading the parents to stress. Participants of the study were all working parents with more than one child in the family. They did not hire a housemaid. Daily routines of both at home and in the office had been very time and energy consuming for the parents. The recent practice of online learning had increased their daily loads and reduced their rest time. The parents also mentioned, they did not have professional knowledge and skills to handle matters in teaching, especially English. Rather being effective in helping the children work the assignments, their teaching to the children at home often caused a polemic. On one hand the parents wanted their children to stay disciplined and focused, while working the assignments fast and accurate; on another hand, the children did the opposite, as a result, both parents and children were involved in unavoidable arguments. For the parents, teaching the children about self-regulation, while managing stresses of their own during the program was truly difficult. Figure 3 below expresses the parents' feeling of being involved in OELL class.

Figure 3

(a) Feeling Emotionally Unstable and (b) Rushed

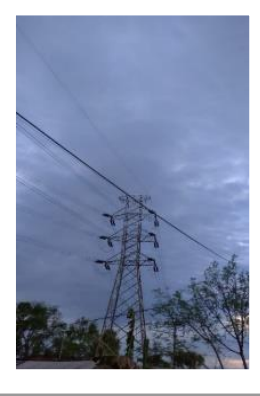

(a)

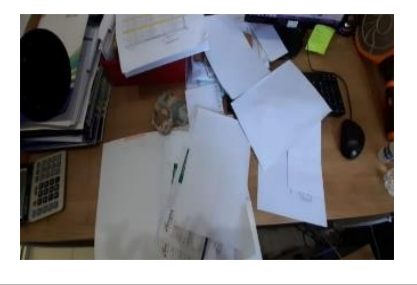

(b)
Supports from School and Government for OELL Program

Supports from both schools and government were available in many kinds. For example: books, internet quota, learning quota, and additional learning tutorials broadcasted via TV, YouTube and some other social media. These supports were beneficial on the side of the parents and their children, yet these were not sufficiently covering all the needs for the learning. In fact, the parents still had to manage their monthly budget to purchase extra-internet quota and buy materials for their children school assignments. Some parents even managed to buy cellphones. Thus, the children could 
join the online learnings, including English, during their school hours. However, not all parents could afford to buy extra-cellphones for their children, considering, they had different financial capabilities. Figure 4 below are the photographs the participants shared to represent what they experienced during the program.

\section{Figure 4}

(a) Need Extra Money for Internet Connection; and (b) Face a Financial Issue

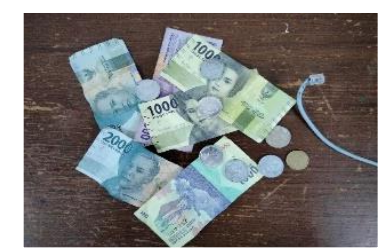

(a)

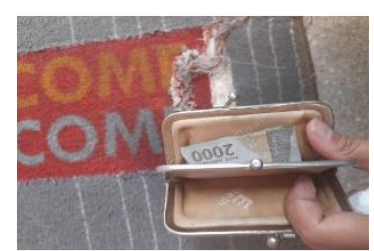

(b)
Our findings noted, most parents selectively managed expenses, especially during this difficult time of pandemic. They were aware that many parents out-there experienced termination of employment. Many of whom were from the middle to low income family. Learning activities required a lot of expenditure would give an extra economic burden to the parents.

Although different kinds of supports had been provided to succeed the OELL program, the parents had never been involved in quality development activities as needed to assist their children in the program, such as workshop and seminar. WhatsApp group was the only forum created by the homeroom teachers, not the English teachers to virtually meet the student parents. Despite being useful, it was used only to update the parents with announcements, learning materials and assignments. Critical discussion, focusing on the application of OELL activities never happened among homeroom teachers, English teachers and the parents.

\section{Parents' Needs and Expectations for OELL Program}

This research had revealed several contextual issues connected to the OELL program. Our findings showed that most parents perceived, the program was impromptu, not well planned and made as an emergency response to Covid-19 pandemic where schools were not allowed to organize offline class at that time. With evidences they witnessed from the program, our findings further indicated that parents presumed stakeholders in the program were not completely ready to deal with the sudden reforms of education. However, they had made efforts to find the most compatible patterns to cope with the situation.

OELL program was completely new for most students, parents and might be for some teachers. Sudden application of this online modes had made especially students and their parents be temporarily at lost. The parents perceived the urgency that future OELL program included their voices. They expected professional guidance to help them handle different situations as required in the program. They added many teachers, especially the old ones were not sufficiently proficient to integrate technological devices into teaching, as a result, some teachers only provided students with books and asked them to work the assignment without online meetings. To the students and their parents, this situation was indeed a problem.

The parents also criticized the effectiveness of both learning materials and the adopted teaching methods to develop their children's English skills and characters. They also stated the recent OELL program less facilitated the students with adequate language exposures and very rarely invited them into physical learning activities. Therefore, the parents suggested that the recent EFL learning materials, learning activities and teaching methods need for improvement to provide the students with better experience of online English language learning.

Adding to the concerns, the parents also voiced that future program of the OELL be conducted in a more flexible way to which blended learning mode with health protocols could be implemented, when the upcoming OELL designs still face many limitations. Lastly, these parents also mentioned another barrier of OELL implementation appertained to the poor quality of internet connection in some areas. To resolve the problem, they hoped both the government and the relevant internet service providers sit together to find solution.

\section{DISCUSSION}

This article not only explored the voices of parents taking a part in the OELL program, but also provided both primary educational and relevant governmental institutions with recommendation to mitigate problems via photovoice. For the parents, their involvement in the project became a means of both exposing the reality affecting their lives and bringing the issue to attention. This section aimed at discussing the findings of what the parents experienced related to the theme and how their voices can be linked to improve the existing OELL program and the relevant policies for primary school education.

\section{Effects of OELL Program from the Lens of Photovoice}

Photovoice provided the parents with a tool to evaluate what they experienced from being involved in the program. By having the parents shared and discussed their most important photographs enclosed with statements about the messages behind 
the photographs, we revealed a number of evidences from their experiences.

Firstly, the recent concept of the OELL program allowed the students not only to experience less significant development of English language skills (Bolster et al., 2004), but also mental health disorders, for example, losing learning concentration and interest (Lau \& Lee, 2020; Zhang et al., 2020), feeling in isolation (Dashtestani, 2020), being indiscipline, dishonest, rebellious to and dependent on their parents and other family members (Cairns et al., 2019). These incidents could potentially be caused by teachers' lack of skills to integrate technology into EFL learning (Taghizadeh \& Hasani Yourdshahi, 2019), students' lack of exposure to the target language and the students' mental unpreparedness to participate in the program, in addition to being affected by the existing poor learning environment, and the absence of social interaction physically involved the students into free play and outdoor activities as they usually had in the offline learning (Dong et al., 2020; Erdogan et al., 2019).

Secondly, poor academic knowledge and skill development of students as compared to the offline program (Dong et al., 2020), including English subject. The parents mentioned methods used in the teaching seemed not to fit the concept of online learning, teachers used one-size-fits-all approach where traditional teaching concept was forced to be applied in the program (Gillett-Swan, 2017). Ignorance on the nature of online learning encouraged by the unpreparedness of the teacher in adopting the concept of the learning caused problems not only for the teachers but also for the students (Amir et al., 2020). As a result, it is important to design online learning activities, which can provide all students with equal opportunity to easily access the content (Armstrong, 2011; Carter et al., 2020; Nugroho et al., 2020; Rice, 2018; Soltanimehr et al., 2019). This situation further highlights the urgency of reconceptualizing teachers' knowledge (Sakhiyya et al., 2018), and mentoring program (Nugroho et al., 2020) from teachers to parents to empower and assist parents with methods of OELL, as well as an insight of practicing critical literacies at home (Sakhiyya \& Hapsari, 2021). The adoption of learning method which fitted students' learning preference played strategic role to create effective learning and increase motivation on the side of the students (Shaw et al., 2019; Stott, 1981; Vereijken et al., 2018). Our study had seen the current concept of the OELL program was mostly geared towards task completion to learn contents instead of developing students' English language skills, self-assessment on understanding, and sense of responsibility to decide what to do when failed a particular subject (Carter et al., 2020), as well as other self-regulatory aspects required for development. Hence, the recent concept of OELL should be reconstructed and managed to focus not only on the content delivery and its outcomes, but also goal-directed learning activities which consider multiple context where students will be involved in (Anderman \& Maehr, 1994; Carter et al., 2020; Schunk et al., 2014).

Thirdly, the application of OELL was revealed to be very much dependent on the online learning infrastructure, such as internet connection. While this connection became an inseparable need for this program, quality of the signal was questionable as it could not technically guarantee equal opportunity for the students to fully participate the program, especially when face to face online meeting was undertaken (Amir et al., 2020; Zhou \& Li, 2020). It was another serious concern in the OELL, not only did a single problem arising in learning processes potentially affect the way the students understood their teachers' instructional messages, but also their learning mood in which it was truly essential for the learning. Some studies reported students with positive mood likely to process information more effectively, than the ones in a negative mood (Brand et al., 2007; Forgas et al., 2009; Isbell, 2004).

Fourthly, other than the issues as reported in the study, the participants who were all career parents with mostly more than one child in the family, mentioned to being physically exhausted as they had to manage time and energy for different tasks and functions; family, office, and their children's online learnings. The absence of professional knowledge of teaching made the situation inconvenient. Rather than effectively escorting the children to work their school duties at home, the parents were often involved in disputes with their children. This was truly a stressful moment for the parents. Although they faced a number of difficulties, problems, and barriers within this unexpected probation of online learning; professional guidance and supports oriented towards developing parents' proficiencies to resolve problems during the program was never available (Dong et al., 2020).

\section{Implication, Limitation, and Future Direction}

Even though the use of digital technology for EFL teaching has gained its popularity, our study on photovoice showed that it is not without unexpected difficulties, thus, the shift of education modes from offline to online has presented challenges for Indonesian parents. In the most general case, with the experiences of being involved in online learning, the parents regarded OELL as a very burdening mode of learning which gave students less educational benefit, thus parents showed rejection to the program and preferred offline mode as compared to the OELL mode for young age education. Being involved in the program, the parents recognized that (1) educational process did not happen the way it should be, the true purpose of EFL teaching had 
been largely abandoned only to complete subject matters in accordance with the curriculum; (2) the parents were neither ready, nor trained to take roles as teacher assistant in the program; (3) Like online learnings for other subjects, OELL required expenditures where many of parents felt financially overwhelmed; (4) the parents found it hard to control their children self-regulation; (5) online learning infrastructure such as internet connection was very poor in some areas, thus learning was distracted; and (6) Participants of the study were all working parents and so they could not be always involved in the program. Although our findings enriched the discussion on the other previous studies, the adoption of photovoice was revealed to have some weaknesses on the side of participants. They found it difficult to find pictures which represented their abstract ideas such progress of EFL learning, stagnancy, dishonest, traditional teaching, being in isolation, and self-regulation. Some mentioned they were not confident at writing, thus not all pictures were equipped with complete narration, but phrases and a couple of sentences, as a result, the data were necessarily explored through in-depth interview. To conclude, quality data of photovoice may provide certain information which other types of data collection methodology found it hard to access, yet it does not mean that photovoice provides stronger and richer data. Types of data from photovoice depend on the way participants making meaning to their social lives. Even though being assigned under the same theme, the participants can still mention their own foci under the same theme for attention where it can likely be different from the other participants. The adoption of photovoice need to be carefully made. It should be neither too strict nor too flexible to avoid the participants from being reluctant to naturally and actively express their lived experiences.

Like other studies, our work had some limitations. While having a small size and range of study conducted in a limited sample of fifteen parents of primary school students, our finding does not necessarily represent the lived experience and perception of both the other parents of the same background and those whose sons or daughters learning English are at university, high-school and other levels of education. Moreover, this study did not compare the parents' voices across variables such as economic, educational and professional backgrounds and gender. Based on the limitation, further research needs to explore parents' voices in broader samples with a wider and more diverse research areas and contexts, and compare its findings with the ones in the present studies to provide more robust and richer understanding on the issue of OELL application.

\section{CONCLUSIONS}

Despite its obstacles, photovoice is worthwhile methodology to qualitative study. This article has shown the potential of photovoice as a methodology and as a unique and transformative space for the parents to reflectively and actively explore the sensitive, solid and overarching topics of OELL as implemented during the pandemic of Covid-19. Through the photographs, the participants shared and critically analyzed their photographs, and found that what mattered them most was the recent concepts and implementation of OELL which they perceived to give parents extra loads, contextual difficulties, and problems as well as challenges. Therefore, it is suggested that educational authorities of both schools and governments review the recently imposed policies on the application of online learnings, including OELL and plan policies geared towards improving current practices of the program. Therefore, the planning should consider multiple contexts such as how, why, and under what condition the OELL program is implemented.

\section{ACKNOWLEDGEMENT}

This study is funded by Indonesia Endowment Fund for Education (LPDP), the Ministry of Finance, Republic of Indonesia.

\section{REFERENCES}

Amir, L. R., Tanti, I., Maharani, D. A., Wimardhani, Y. S., Julia, V., Sulijaya, B., \& Puspitawati, R. (2020). Student perspective of classroom and distance learning during COVID-19 pandemic in the undergraduate dental study program Universitas Indonesia. BMC Medical Education, 20(1), 1-8. https://doi.org/10.1186/s12909-020-02312-0

Anderman, E. M., \& Maehr, M. L. (1994). Motivation and schooling in the middle grades. Review of Educational Research, 64(2), 287-309. https://doi.org/10.3102/00346543064002287

Anderson, V., Rabello, R., Wass, R., Golding, C., Rangi, A., Eteuati, E., Bristowe, Z., \& Waller, A. (2019). Good teaching as care in higher education. Higher Education. https://doi.org/10.1007/s10734-019-00392-6

Anitha Kumari, T., Hemalatha, C. H., Subhani Ali, M., \& Naresh, R. (2020). Survey on impact and learning's of the online courses on the present era. Procedia Computer Science, 172, 82-91. https://doi.org/10.1016/j.procs.2020.05.167

Armstrong, D. A. (2011). Students' perceptions of online learning and instructional tools: A qualitative study of undergraduate students use of online tools. Turkish Online Journal of Educational Technology, 10(3), 222-226. http://www.tojet.net/articles/v10i3/10325.pdf 
Arnott, L., \& Yelland, N. (2020). Multimodal lifeworlds : pedagogies for play inquiries and explorations. Journal of Early Childhood Education Research, 9(1), 124-146. https://jecer.org/wpcontent/uploads/2020/02/Arnott-Yellandissue9-1.pdf

Aubrey, C., \& Dahl, S. (2008). A review of the evidence on the use of ICT in the early years foundation stage. Education, March, 107. http://wrap.warwick.ac.uk/46079/

Bennett, N. J., \& Dearden, P. (2013). A picture of change: Using photovoice to explore social and environmental change in coastal communities on the Andaman Coast of Thailand. Local Environment, 18(9), 9831001 . https://doi.org/10.1080/13549839.2012.74873 3

Bolster, A., Balandier-Brown, C., \& Rea-Dickins, P. (2004). Young learners of modern foreign languages and their transition to the secondary phase: A lost opportunity? Language Learning Journal, 30(1), 35-41. https://doi.org/10.1080/09571730485200211

Brand, S., Reimer, T., \& Opwis, K. (2007). How do we learn in a negative mood? Effects of a negative mood on transfer and learning. Learning and Instruction, 17(1), 1-16. https://doi.org/10.1016/j.learninstruc.2006.11. 002

Braun, V., \& Clarke, V. (2006). Applied Qualitative Research in Psychology. Applied Qualitative Research in Psychology, 3(2), 77101. https://doi.org/10.1057/978-1-13735913-1

Cairns, K., Potter, S., Nicholas, M., \& Buhagiar, K. (2019). Development of ReachOut Parents: a multi-component online program targeting parents to improve youth mental health outcomes. Advances in Mental Health, 17(1), 55-71.

https://doi.org/10.1080/18387357.2018.14760 67

Carter, R. A., Rice, M., Yang, S., \& Jackson, H. A. (2020). Self-regulated learning in online learning environments: strategies for remote learning. Information and Learning Science, 121(5-6), 311-319. https://doi.org/10.1108/ILS-04-2020-0114

Castleden, H., Garvin, T., \& First Nation, H. ay aht. (2008). Modifying Photovoice for community-based participatory Indigenous research. Social Science and Medicine, 66(6), 1393-1405. https://doi.org/10.1016/j.socscimed.2007.11.0 30

Ciolan, L., \& Manasia, L. (2017). Reframing Photovoice to Boost Its Potential for Learning Research. International Journal of Qualitative
Methods, 16(1), 1-15.

https://doi.org/10.1177/1609406917702909

Clements, D. H., \& Sarama, J. (2003). Young Children and Technology: What Does the Research Say? National Association for the Education of Young Children, 58(6), 34-40. http://www.jstor.org/stable/42729004

Cook, K., Brown, A., \& Ballard, G. (2016). Using Photovoice to Explore Environmental Sustainability Across Languages and Cultures. Discourse and Communication for Sustainable Education, 7(1), 49-67. https://doi.org/10.1515/dcse-2016-0004

Dashtestani, R. (2020). Online courses in higher education in Iran: A stakeholder-based investigation into preservice teachers' acceptance, learning achievements, and satisfaction: A mixed-methods study. International Review of Research in Open and Distance Learning, 21(4), 117-142. https://doi.org/10.19173/IRRODL.V21I4.4873

Dodson, L., \& Schmalzbauer, L. (2005). Poor mothers and habits of hiding: Participatory methods in poverty research. Journal of Marriage and Family, 67(4), 949-959. https://doi.org/10.1111/j.17413737.2005.00186.x

Dong, C., Cao, S., \& Li, H. (2020). Young children's online learning during COVID-19 pandemic: Chinese parents' beliefs and attitudes. Children and Youth Services Review, 118(June), 105440. https://doi.org/10.1016/j.childyouth.2020.105 440

Erdogan, N. I., Johnson, J. E., Dong, P. I., \& Qiu, Z. (2019). Do parents prefer digital play? Examination of parental preferences and beliefs in four nations. Early Childhood Education Journal, 47(2), 131-142. https://doi.org/10.1007/s10643-018-0901-2

Evans-Agnew, R. A., \& Rosemberg, M. A. S. (2016). Questioning photovoice research: Whose voice? Qualitative Health Research, 26(8), 1019-1030. https://doi.org/10.1177/1049732315624223

Ferdiansyah, S., Widodo, H. P., \& Elyas, T. (2020). Photovoice in the English as an additional language (EAL) writing classroom: No need to rush to love writing because love will grow with time. Journal of Asia TEFL, 17(2), 463478.

https://doi.org/10.18823/asiatefl.2020.17.2.10. 463

Forgas, J. P., Goldenberg, L., \& Unkelbach, C. (2009). Can bad weather improve your memory? An unobtrusive field study of natural mood effects on real-life memory. Journal of Experimental Social Psychology, 45(1), 254-257. https://doi.org/10.1016/j.jesp.2008.08.014 
Gillett-Swan, J. (2017). The challenges of online learning: Supporting and engaging the isolated learner. Journal of Learning Design, 10(1), 20. https://doi.org/10.5204/jld.v9i3.293

Grant, J. (2019). Language and education: Photovoice workshops and the !Xun and Khwe bushmen. Critical Arts, 33(4-5), 157173. https://doi.org/10.1080/02560046.2019.16632 28

Green, E., \& Kloos, B. (2009). Facilitating youth participation in a context of forced migration: A photovoice project in northern Uganda. Journal of Refugee Studies, 22(4), 461-482. https://doi.org/10.1093/jrs/fep026

Isbell, L. M. (2004). Not all happy people are lazy or stupid: Evidence of systematic processing in happy moods. Journal of Experimental Social Psychology, 40(3), 341-349. https://doi.org/10.1016/j.jesp.2003.06.003

Joyce, H. D. (2018). Using photovoice to explore school connection and disconnection. Children and Schools, 40(4), 211-219. https://doi.org/10.1093/cs/cdy021

Kim, K. J., Liu, S., \& Bonk, C. J. (2005). Online MBA students' perceptions of online learning: Benefits, challenges, and suggestions. Internet and Higher Education, 8(4 SPEC. ISS.), 335344. https://doi.org/10.1016/j.iheduc.2005.09.005

Kumi-Yeboah, A., Kim, Y., Sallar, A. M., \& Kiramba, L. K. (2020). Exploring the use of digital technologies from the perspective of diverse learners in online learning environments. Online Learning Journal, 24(4), 42-63. https://doi.org/10.24059/olj.v24i4.2323

Lan, P. S., Liu, M. C., \& Baranwal, D. (2020). Applying contracts and online communities to promote student self-regulation in English learning at the primary-school level. Interactive Learning Environments. https://doi.org/10.1080/10494820.2020.17896 74

Lau, E. Y. H., \& Lee, K. (2020). Parents' views on young children's distance learning and screen time during COVID-19 class suspension in Hong Kong. Early Education and Development. https://doi.org/10.1080/10409289.2020.18439 25

Lorusso, J. R., Johnson, A. M., Morrison, H. J., Stoddart, A. L., Borduas, C., Cameron, N., Lim, C., \& Price, C. (2020). Graduate student experience in focus: a photovoice investigation of physical and health education graduate students in Canada. Physical Education and Sport Pedagogy, 1-23. https://doi.org/10.1080/17408989.2020.17895 72
Malka, M. (2020). Photo-voices from the classroom: photovoice as a creative learning methodology in social work education. Social Work Education, 00(00), 1-17. https://doi.org/10.1080/02615479.2020.17890 91

Mishra, D. L., Gupta, D. T., \& Shree, D. A. (2020). Online teaching-learning in higher education during lockdown period of COVID-19 pandemic. International Journal of Educational Research Open, June, 100012. https://doi.org/10.1016/j.ijedro.2020.100012

Mulder, C., \& Dull, A. (2014). Facilitating selfreflection: The integration of photovoice in graduate social work education. Social Work Education, 33(8), 1017-1036. https://doi.org/10.1080/02615479.2014.937416

Nugroho, K. Y., Sakhiyya, Z., Saleh, M., Mujiyanto, J., \& Rukmini, D. (2020). Exploring the constructivist mentoring program in developing EFL teacher professionalism: A qualitative approach. Indonesian Journal of Applied Linguistics, 10(1), 132-142. https://doi.org/10.17509/ijal.v10i1.25021

Okumura, S. (2020). Design and implementation of a telecollaboration project for primary school students to trigger intercultural understanding. Intercultural Education, 31(4), 377-389. https://doi.org/10.1080/14675986.2020.17525 46

Perry, B. (2006). Using photographic images as an interactive online teaching strategy. Internet and Higher Education, 9(3), 229-240. https://doi.org/10.1016/j.iheduc.2006.06.008

Pierce, J. M. (2020). Photovoice: documenting lives in aquaculture and fisheries through a gendered photo lens. Gender, Technology and Development, 24(1), 131-154. https://doi.org/10.1080/09718524.2020.17326 63

Plowman, L., McPake, J., \& Stephen, C. (2012). Extending opportunities for learning: the role of digital media in early education. In Contemporary debates in childhood education and development. https://doi.org/10.4324/9780203115558

Rasheed, R. A., Kamsin, A., \& Abdullah, N. A. (2020). Challenges in the online component of blended learning: A systematic review. Computers and Education, 144(March 2019), 103701. https://doi.org/10.1016/j.compedu.2019.103701

Rice, M. F. (2018). Supporting literacy with accessibility: Virtual school course designers' planning for students with disabilities. Online Learning Journal, 22(4), 161-179. https://doi.org/10.24059/olj.v22i4.1508

Sakhiyya, Z., Agustien, H. I. R., \& Pratama, H. (2018). The reconceptualisation of knowledge 
base in the pre-service teacher education curriculum: Towards ELF pedagogy. Indonesian Journal of Applied Linguistics, 8(1), 49-56. https://doi.org/10.17509/ijal.v8i1.11464

Sakhiyya, Z., \& Hapsari, C. T. (2021). Critical Literacies in Indonesia. In J. Zacher Pandya, R. A. Mora, J. H. Alford, N. A. Golden, \& R. S. de Roock (Eds.), The Handbook of critical literacies (pp. 169-176). Routledge. https://doi.org/10.4135/9781483385198.n67

Schunk, D., Meece, J., \& Pintrich, P. (2014). Motivation in Education Theory, Research and Application (4th ed.). Pearson Education Limited.

Seitz, C. M., Strack, R. W., Rice, R., Moore, E., Duvall, T., \& Wyrick, D. L. (2012). Using the photovoice method to advocate for change to a campus smoking policy. Journal of American College Health, 60(7), 537-540. https://doi.org/10.1080/07448481.2012.688781

Shaw, T. J., Yang, S., Nash, T. R., Pigg, R. M., \& Grim, J. M. (2019). Knowing is half the battle: Assessments of both student perception and performance are necessary to successfully evaluate curricular transformation. PLoS ONE, 14(1), 1-13. https://doi.org/10.1371/journal.pone.0210030

Soltanimehr, E., Bahrampour, E., Imani, M. M., Rahimi, F., Almasi, B., \& Moattari, M. (2019). Effect of virtual versus traditional education on theoretical knowledge and reporting skills of dental students in radiographic interpretation of bony lesions of the jaw. BMC Medical Education, 19(1), 1-7. https://doi.org/10.1186/s12909-019-1649-0

Stott, D. H. (1981). Behaviour disturbance and failure to learn: A study of cause and effect. Educational Research, 23(3), 163-172. https://doi.org/10.1080/0013188810230301

Stupans, I., Baverstock, K., \& Jackson, M. (2019). Photo-essay as an assessment strategy for learning about the determinants of health: Students' experiences. Collegian, 26(1), 146150 . https://doi.org/10.1016/j.colegn.2018.07.002

Taghizadeh, M., \& Hasani Yourdshahi, Z. (2019). Integrating technology into young learners' classes: language teachers' perceptions. Computer Assisted Language Learning, 1-25. https://doi.org/10.1080/09588221.2019.1618876

Tay, L. Y., Lim, C. P., Nair, S. S., \& Lim, S. K. (2014). Online software applications for learning: Observations from an elementary school. Educational Media International, 51(2), 146-161. https://doi.org/10.1080/09523987.2014.924663

Tsang, K. K., \& Lian, Y. (2020). Understanding the reasons for academic stress in Hong Kong via photovoice: implications for education policies and changes. Asia Pacific Journal of Education, 00(00), 1-12.

https://doi.org/10.1080/02188791.2020.1772719

Vereijken, M. W. C., van der Rijst, R. M., van Driel, J. H., \& Dekker, F. W. (2018). Student learning outcomes, perceptions and beliefs in the context of strengthening research integration into the first year of medical school. Advances in Health Sciences Education, 23(2), 371-385. https://doi.org/10.1007/s10459-017-9803-0

Wall, K., \& Higgins, S. (2006). Facilitating metacognitive talk: A research and learning tool. International Journal of Research and Method in Education, 29(1), 39-53. https://doi.org/10.1080/01406720500537353

Wang, C., \& Burris, M. A. (1994). Empowerment through Photo Novella: Portraits of Participation. Health Education \& Behavior, 21(2), 171-186. https://doi.org/10.1177/109019819402100204

Wang, C., \& Burris, M. A. (1997). Photovoice: Concept, Methodology, and Use for Participatory Needs Assessment. Health Education and Behavior, 24(3), 369-387. https://doi.org/10.1177/109019819702400309

Wang, C. C., Morrel-Samuels, S., Hutchison, P. M., Bell, L., \& Pestronk, R. M. (2004). Flint photovoice: Community building among youths, adults, and policymakers. American Journal of Public Health, 94(6), 911-913. https://doi.org/10.2105/AJPH.94.6.911

Wang, Z., Pang, H., Zhou, J., Ma, Y., \& Wang, Z. (2021). "What if...it never ends?": Examining challenges in primary teachers' experience during the wholly online teaching. Journal of Educational Research, 114(1), 89-103. https://doi.org/10.1080/00220671.2021.1884823

Wass, R., Anderson, V., Rabello, R., Golding, C., Rangi, A., \& Eteuati, E. (2020). Photovoice as a research method for higher education research. Higher Education Research and Development, 39(4), 834-850. https://doi.org/10.1080/07294360.2019.1692791

World Bank. (2020). The Promise of Education in Indonesia. https://www.worldbank.org/en/ country/indonesia/publication/the-promise-ofeducation-in-indonesia

Zhang, W., Wang, Y., Yang, L., \& Wang, C. (2020). Suspending classes without stopping learning: China's education emergency management policy in the COVID-19 outbreak. Journal of Risk and Financial Management, 13(3), 55. https://doi.org/10.3390/jrfm13030055

Zhou, L., \& Li, F. (2020). Review of the Largest Online Teaching in China during the COVID19. 5(1), 550. https://doi.org/10.15354/bece.20.re040 